\title{
Immersive Virtual Reality for the Management of Pain in Community-Dwelling Older Adults.
}

\author{
Sara Benham \\ University of the Sciences \\ Minhee Kang \\ University of the Sciences \\ Namrata Grampurohit \\ Thomas Jefferson University
}

Follow this and additional works at: https://jdc.jefferson.edu/otfp

Part of the Geriatrics Commons, and the Occupational Therapy Commons

Let us know how access to this document benefits you

\section{Recommended Citation}

Benham, Sara; Kang, Minhee; and Grampurohit, Namrata, "Immersive Virtual Reality for the Management of Pain in Community-Dwelling Older Adults." (2018). Department of Occupational Therapy Faculty Papers. Paper 64.

https://jdc.jefferson.edu/otfp/64

This Article is brought to you for free and open access by the Jefferson Digital Commons. The Jefferson Digital Commons is a service of Thomas Jefferson University's Center for Teaching and Learning (CTL). The Commons is a showcase for Jefferson books and journals, peer-reviewed scholarly publications, unique historical collections from the University archives, and teaching tools. The Jefferson Digital Commons allows researchers and interested readers anywhere in the world to learn about and keep up to date with Jefferson scholarship. This article has been accepted for inclusion in Department of Occupational Therapy Faculty Papers by an authorized administrator of the Jefferson Digital Commons. For more information, please contact: JeffersonDigitalCommons@jefferson.edu. 
Immersive Virtual Reality for the Management of Pain in Community-Dwelling Older Adults

\begin{abstract}
Background: Immersive virtual reality (VR) can provide a high-level of engagement and distraction analgesia to address pain. However, community-based applications of this technology for older adults have not been studied. Objective: To examine the applicability and effectiveness of an immersive VR intervention for pain, depression, and quality of life (QOL) in older adults. Methods: This pretest-posttest, mixed-methods design included senior center members $(n=12)$ with pain that interfered with daily functioning. The outcomes included the Numerical Pain Rating Scale, PROMIS® depression scale, WHO-BREF QOL, and open-ended questions. Results: The VR intervention (15-45 minute sessions, 12 sessions over six weeks) was wellaccepted with no drop-outs. There was a significant decrease in pain $(p=0.002, d=-1.54)$ with no effect on depression and QOL. There were no adverse effects and positive perceptions of VR were reported. Conclusion: The six-week immersive VR intervention was applicable and effective in reducing pain intensity for community-dwelling older adults.
\end{abstract}


Immersive Virtual Reality for the Management of Pain in Community-Dwelling Older Adults

\section{Introduction}

Occupational therapy interventions for the older adult promote engagement in meaningful daily activities that are interrupted when one experiences pain. About $73 \%$ of communitydwelling older adults experience pain related to depression, decreased quality of life, and decreased social interaction leading to overall lack of engagement in daily activities (Parmelee, Katz, \& Lawton, 1991; Rustøen et al., 2005; Schofield, 2007). Over 116 million U.S. adults, regardless of age, suffer from a chronic pain condition (Tsang et al., 2008). Community-based occupational therapy interventions to address pain need to be engaging for high compliance and improved outcomes. Advances in technology, particularly virtual reality, provide a high level of engagement and can increase compliance for intervention programs and thereby improve outcomes for older adults. Virtual reality studies in older adults have reported high levels of engagement using systems such as Oculus Rift (www.oculus.com), contrary to common myths of dislike towards technology among older adults (Chesham, Wyss, Müri, Mosimann, \& Nef, 2007; Kim, Darakjian, \& Finley, 2017).

Virtual reality (VR) allows users to actively engage in the virtual world, with nonimmersive (e.g., IREX [http://www.gesturetekhealth.com]; BrightBrainer [www.brightbrainer.com]) and immersive applications (e.g., HTC-Vive [www.vive.com]). Immersive VR involves a head-mounted display which allows the users to experience the virtual world more realistically through a multisensory approach. The evidence of the benefits of VR, including its physical and psychological effects, is growing (Malloy \& Milling, 2010). Researchers suggest that VR distraction occurs during a limitation of pain processing, by using emotional and attentional cognitive processes to facilitate an analgesic effect (Li, Montaño, Chen 
\& Gold, 2011). Malloy \& Milling (2010) reported in a systematic review that VR distraction, defined as utilizing audio-visual goggles or helmet with an opportunity to interact with computer-simulated environments, is effective in decreasing pain intensity during burn injury care and other procedures across multiple clinical settings. A recent study reported a significant decrease of pain using a standard 11-point numeric rating scale when utilizing the Samsung Gear Oculus for the VR intervention, as compared to a two-dimensional video (Tashjian et al., 2017). The study was conducted with a wide age-range of hospitalized patients in acute care, but the effects could be enhanced in community-based settings with participants with a presumably stable health status. However, the community-based applications of VR are lacking, particularly for older adults who routinely experience pain. Thus, the focus of this study was to measure the effects of a VR intervention on pain intensity and the closely related factors of depression and quality of life, as well as tracking the perceived experiences of the participant to gauge applicability of VR. This prompted an examination into our research questions: What is the efficacy of a VR intervention on pain, depression, and quality of life of community-dwelling older adults who experience pain? What is the applicability of a community-based immersive VR intervention for pain in community-dwelling older adults?

\section{Methods}

\section{Study Design}

This mixed methods, exploratory study included a within-subject pretest-posttest design and was followed by an open-ended survey questionnaire upon closure of the intervention. This study was conducted at a senior day center in $\mathrm{xxx}$ that provides resources and programs to community-dwelling adults over the age of 55.

\section{Study Procedure}


The xxx Institutional Review Board provided ethical approval for this study and all participants provided informed consent for participation, which included the study's risks and benefits and that their participation was voluntary. Information flyers were distributed throughout the center for recruitment, with the recruitment period open for four months. Any individuals who were interested in the study were provided the opportunity to screen for inclusion. After providing consent, potential participants completed an initial screening with a nine-question demographic intake form and the Mini-Cog (Borson, 2016). The Mini-Cog is a quick, three-step screening to rule out the likelihood of dementia, with comparable specificity and sensitivity to the Mini Mental State Exam completed in less administration time (Tsoi, Chan, Hirai, Wong, \& Kwok, 2015). Permission to utilize Mini-Cog for research purposes was granted by the author. Inclusion criteria were: self-reported pain (not specified as chronic or acute), the pain interfered in daily functioning (self-reported as "yes" to the question "Does the pain bother you?"), attendance at the senior center (serving ages 55 and over) at least two days per week, and self-reported intact or corrected vision. Participants were excluded if they self-reported a history of vertigo, seizures, and/or epilepsy to prevent exacerbation of those symptoms as potential VR side effects (Pot-Kolder, Veling, Counotte, \& Van Der Gaag, 2018). Individuals scoring less than four on the Mini-Cog were excluded to ensure that all participants could demonstrate the mental process skills to understand and attend to the VR programming (Borson, Scanlan, Brush, Vitaliano, \& Dokmak, 2000). Participant baseline characteristics data are included in Table 1.

\section{Intervention}

All participants organized their individual session schedules with one researcher. Each session length was at least 15 minutes and no longer than 45 minutes utilizing a commerciallyavailable immersive VR system, the HTC Vive ${ }^{\mathrm{TM}}$ (www.vive.com). The HTC Vive ${ }^{\mathrm{TM}}$ consists of 
head-mounted display and two hand controllers, with activities supervised and guided by the researcher through a computer monitor display (Figure 1). The participants each completed a total of 12 VR sessions over six weeks (approximately two sessions per week). Within the Viveport (https://www.viveport.com) or Steam VR (https://store.steampowered.com/) library, many activity options are available to users. Games were continuously downloaded throughout the study as the researcher learned of participants' occupational interests. From the downloaded library, participants chose their games for each session. Games requiring standing and movement were eliminated for safety. Popular games included engagement with pets, exploration of animals, interactive music games, and travel. For example, the travel application explored a destination from a three-dimensional globe. The researcher reminded participants to request to end the session at any time if they experienced adverse symptoms, or for any other reason. Participants were reminded to remain seated throughout all sessions for safety, except one participant who attempted to engage in the activity while standing. Prior to the VR activity, the participants were asked to score their pain on the Numerical Pain Rating Scale (NPRS). For consistency, participants were asked to report the same pain location at the post-intervention as reported at the first session.

\section{Assessments}

The assessments included Numerical Pain Rating Scale (NPRS), Patient-Reported Outcomes Measurement Information System (PROMIS®) Item Bank v. 1.0 - Emotional Distress - Depression, and the World Health Organization's Quality of Life Scale Brief Version (WHOQOL-BREF), pre and post intervention.

The pain intensity was scored on the Numerical Pain Rating Scale (NPRS). NPRS is an 11-point scale, ranging from zero to 10, with a report of zero as "no pain" and 10 as "the worst 
pain ever experienced" (Farrar, 2001). The NPRS has poor reproducibility when verbal anchors, such as "10 being the worst pain," are used inconsistently (Williamson \& Boggart, 2005). However, the NPRS with 11-point scale has high sensitivity and the failure rate of the NPRS is only two percent (Williamson \& Boggart, 2005). The NPRS scores on pre-session 1 and postsession 12 were used as the pretest-posttest measurement outcomes of pain.

Changes in quality of life (QOL) and depression were measured on the WHOQOL-BREF and the PROMIS® Item Bank v. 1.0 - Emotional Distress - Depression, respectively (The WHOQOL Group, 1998; PROMIS Health Organization and PROMIS Cooperative Group, 2016). WHOQOL-BREF is comprised of 26 questions that are answered on a five-point scale between one (never, not at all, very dissatisfied, very poor) and five (always, extremely/extreme amount, very satisfied, very well). The authors of the WHOQOL-BREF granted permission to utilize WHOQOL-BREF for this research. The WHOQOL-BREF has acceptable internal consistency reliability (Cronbach's alpha $>0.7)$, significant discriminant validity $(\mathrm{p}<0.0001)$, and strong construct validity for total populations and domains $(\mathrm{p}<0.0001)$ (Skevington, Lofty, \& O’Connell, 2004). The PROMIS® also utilizes a five-point rating scale with 27 total items. The PROMIS® depression subscale has high internal consistency and reliability (Cronbach's alpha >0.98) and inter-item correlation (0.64) (Choi, Schalet, Cook, \& Cella, 2014). The individual items may be analyzed in short forms, if necessary (PROMIS Health Organization and PROMIS Cooperative Group, 2016). Raw scores for the PROMIS® were calculated online via assessmentcenter.net (HealthMeasures, 2018). In addition, the participants completed an openended questionnaire form at the conclusion of Session 12. The questionnaire included five items probing the participant's experience with VR as shown in Table 2.

\section{Data analysis}


The statistical software, SPSS, was used for quantitative data analysis (SPSS Version 24.0; IBM Corp.; Armonk, NY). A check for normality indicated non-normal distribution. Thus, nonparametric tests were utilized to examine pretest-posttest changes using the Wilcoxon signedrank test, with significance set at 5\%. The effect size and confidence interval estimates were computed using Cohen's $d$ (Cohen, 1988). Content analysis for the qualitative data from open ended questions used a conceptual analysis framework as suggested by Schreier (2014) and with steps outlined by Rossi, Serralvo, \& Joao (2014). The plan for original content analysis involved four areas of applicability related to overall experience, symptoms, usability, and recommendations for future use. Although the questions were designed to gain insight into these areas, the written responses of participants were in the form of one word, a phrase, or a sentence. Detailed participant responses for an in-depth content analysis were lacking. Thus, the coding framework was revised to categorize the content of the responses as positive or negative and to quantify the frequency of occurrence of the positive or negative codes.

\section{Results}

A total of 15 participants were recruited and consented to participate in screening questions for the study. Three were excluded (due to cognitive impairment), resulting in 12 total participants who provided informed consent for the full study. The Wilcoxon signed-rank test revealed that posttest pain was significantly lower than pretest pain with a large effect size $(p=$ $0.002, d=-1.54$, confidence interval $=-2.50,-0.58)$. The results of the PROMIS $®$ and WHOQOL-BREF did not indicate significant changes (Table 3). There were no severe adverse effects reported during the duration of the study, for all participants.

The median pretest PROMIS® depression scale score was $54.5(\overline{\mathrm{x}}=53.5)$ and the posttest PROMIS® depression scale score was lower at $43.5(\overline{\mathrm{x}}=49.1)$. The depression scale 
changes were not statistically significant $(p=0.33, d=0.29)$. The individual pretest-posttest item responses on the PROMIS® were analyzed and two questions were found to have significant changes; Item EDDEP 19- "I felt that I wanted to give up on everything" ( $p=0.025)$ and Item EDDEP 26- "I felt disappointed in myself” $(p=0.025)$ revealed significant differences. The pretest-posttest differences of the WHOQOL-BREF scoring were not significant (Overall Health $p=0.66$; Physical $p=0.08$, Psychological $p=0.15$; Social $p=0.87$; Environment $p=0.92$ ). Although no significant WHOQOL-BREF differences were observed in any domains, note that when run one-tailed (data not reported), the Physical Domain differences were significant.

Content analysis of the survey questions was done by one author (MK) for positive and negative perspectives. The two other authors $(\mathrm{SB}, \mathrm{NG})$ reviewed and confirmed the codes. The analysis revealed that $100 \%$ of participants reported overall positive experiences with the VR system, with $100 \%$ reporting that the VR positively affected their experiences of their pain levels (Table 2). Upon retrospective chart review, participants had various diagnoses that contributed to pain such as chronic back or shoulder pain, arthritis, neuropathy, history of fractures, and edema. $47.1 \%$ of participants shared that they experienced an undesirable symptom, but upon further investigation, all symptoms were related to a specific activity that could be avoided within the game or program in future use. $91.7 \%$ of participants reported that they would continue to use the system if they were given the chance, with $100 \%$ of participants reporting that they would recommend the device to other members of the senior center.

\section{Discussion}

The primary purpose of this study was to examine the efficacy of a community-based immersive virtual reality intervention for older adults with pain. The results indicate that the intervention is effective in significantly improving pain $(p<0.05)$ for the participants. The 
findings of this study were consistent with current literature suggesting a pain decrease after VR engagement, for at least 15 minutes (Wiederhold, Gao, Sulea, \& Wiederhold, 2014). Utilizing a mixed methodology, the survey results indicated that the VR experience for older adults provides some distraction from pain, and is feasible and enjoyable. Based on the open-ended survey, all participants reported that the application of VR affected their pain level. Regarding the experience with VR, one individual responded that pain reduced significantly enough for her to purchase her own VR equipment [Code 09]. Upon further investigation, some participants reported that they were distracted from the pain because they were preoccupied with the VR activity, reporting "it made me forget about pain" [Code 02], "I did not feel pain because I was so engrossed in the VR experience" [Code 04], and that the VR was a "great distraction" [Code 09]. It is also notable that one participant described his own self-awareness of a distinction between physical and psychological experiences of pain, and that he experienced a decrease in pain related to both aspects [Code 14]. Although evidence is emerging to support the phenomenon of altered bodily consciousness with VR (Pozeg et al., 2017; Gilpin, Bellan, Gallace, \& Moseley, 2014), our participants also reported feeling altered perceptions, with one participant reporting that she felt the decrease in pain because the VR "took me out of my body" in relation to the effect on pain [Code 05]. Some authors report that pain only subsides during the VR experience with no substantial carryover (Garrett, Taverner, \& McDade, 2017; Shin et al., 2016). Our study is limited by the time points of pain reports, specifically, a lack of pain reports outside of the VR experience and a follow-up assessment. Future studies should further explore the withstanding length of the altered perception of pain after VR sessions.

The secondary objectives were to examine the impact of immersive VR on QOL and depression, which were both not significant from pre to post intervention. The Physical domain 
of QOL approached significance $(p=0.0800)$ which supports recent reviews that the use of VR interventions enable physical activity and improve health for older adults (Miller et al., 2014). The effect may be due to physical changes having a greater impact on meaningful, daily life activities, making for enhanced reporting as well. For example, one participant who was eager to use VR during the study attended sessions with forearm crutches and a portable oxygen device in the initial period, and toward the last few sessions, she did not use crutches and the portable oxygen device was only used as needed [Code 09]. However, there were other participants who continued to use mobility devices throughout. The one participant's higher overall dosage due to engagement in VR beyond the intervention sessions may have contributed to this effect and dose-response aspects need to be further investigated. Other perceptions of physical capabilities such as shoulder movements may have been enhanced, as VR controller use increased shoulder movement and range, thereby contributing to upper extremity physical gains. However, this study did not conduct the measurement of physical function due to the community-based emphasis of the research. Future studies in a more controlled environment can better monitor the physical function gains by measuring assistive device use, strength, endurance, and range of motion.

No participants were clinically diagnosed with depression which may have contributed to the lack of significant change in overall scores on depression. The PROMIS $®$ was an appropriate measurement for this study with two significant item statements ("I wanted to give up on everything" and "I felt disappointed in myself"). These items possibly were related to a sense of accomplishment in a virtual, meaningful occupation that the client may not be able to participate in, outside of a VR platform. For future studies, a PROMIS® short form version could include more applicable, specific items. Also, the measurements used may have been too general to 
measure specific life stressors, i.e. caregiver burden. It may be beneficial to measure occupational roles by utilizing assessments such as Canadian Occupational Performance Measure (Law et al., 2014) or to explore if the experience was enjoyable because the sessions were occupation-based and meaningful to the client.

The participants' reports of the experiences were mostly positive and all enjoyed the VR's unique ability to provide immersive experiences. Although these findings are not consistent with Tashjian and colleagues' (2017) report of older individuals unwillingness to try VR technology, their population was based in a hospital setting. The physical context of a hospital versus a community-based setting could influence VR participation willingness. The medical needs and relative ability to engage in a meaningful, occupation-based gaming experience may become less of a priority for older adults within the hospital setting. The participants in our study were overwhelmingly enthusiastic about the technology and were willing to share their experiences with their peers. Self-selection bias and the location of this senior center in an urban neighborhood with primarily middle-class families may influence these results of applicability. Future studies should seek to recruit a wider sampling of older adults, including those limited in having prior experiences with technology.

The nature of immersive VR is known to cause motion sickness due to visual conflict giving rise to adverse reactions such as nausea and dizziness, referred to as cybersickness (PotKolder, Veling, Counotte \& Van Der Gaag, 2018). In this study, seven out of 12 participants $(58.3 \%)$ stated that they did not experience any symptoms in any of the 12 monitored sessions. Four participants only experienced symptoms of nausea and dizziness when in particular settings such as tight space, high altitude, and fast moving speed. One person responded that neck discomfort (from a previous mild musculoskeletal disorder) was aggravated due to the weight of 
the head-mounted display. Immersive VR may present with adverse reactions and it is thus recommended that the VR system is used with adequate monitoring and supervision when used with older adults.

In addition to the aforementioned limitations, others include the small sample size, one location for sampling a population of community-dwelling older adults, the self-selection bias of recruitment methods, and that the current study is exploratory and limited in scope. Information from the post-intervention survey questionnaire will help to provide appropriate supports for our follow-up study such as using a trained volunteer for assistance with all VR sessions. A final limitation of this study is that the measures and interventions were administered by the same researcher. For a more robust research design, future examinations should employ blinded evaluators.

\section{Conclusion}

For the 12 participants in this six-week study, an immersive VR intervention appears to have improved pain intensity in community-dwelling older adults with no effect on depression and quality of life. The findings suggest that immersive VR may be a feasible, enjoyable, and occupation-based preparatory method for the management of pain for older adults. Future research with a powered randomized control trial is needed to examine the effectiveness of this intervention over occupational therapy standard of care modalities for pain. 


\section{References}

Borson, S. (2016). Mini-Cog@. Retrieved from https://mini-cog.com/mini-coginstrument/standardized-mini-cog-instrument/

Borson, S., Scanlan, J., Brush, M., Vitaliano, P., \& Dokmak, A. (2000). The mini-cog: a cognitive 'vital signs' measure for dementia screening in multi-lingual elderly. International Journal of Geriatric Psychiatry, 15(11), 1021-1027. doi: 10.1002/10991166(200011)15:11<1021::AID-GPS234>3.0.CO;2-6

Chesham, A., Wyss, P., Müri, R. M., Mosimann, U. P., \& Nef, T. (2017). What older people like to play: Genre preferences and acceptance of casual games. JMIR Serious Games, 5(2), e8. doi: 10.2196/games.7025

Choi, S. W., Schalet, B., Cook, K. F., \& Cella, D. (2014). Establishing a common metric for depressive symptoms: Linking the BDI-II, CES-D, and PHQ-9 to PROMIS Depression. Psychological Assessment, 26(2), 513-527. doi:10.1037/a0035768

Cohen, J. (1988). Statistical power analysis for the behavioral sciences (2nd ed.). Hillsdale, NJ: Erlbaum.

Farrar, J. T., Young Jr, J. P., LaMoreaux, L., Werth, J. L., \& Poole, R. M. (2001). Clinical importance of changes in chronic pain intensity measured on an 11-point numerical pain rating scale. Pain, 94(2), 149-158. doi: 10.1016/S0304-3959(01)00349-9

Garrett, B., Taverner, T., \& McDade, P. (2017). Virtual reality as an adjunct home therapy in chronic pain management: An exploratory study. JMIR Medical Informatics, 5(2), e11. http://doi.org/10.2196/medinform.7271

Gilpin, H. R., Bellan, V., Gallace, A., \& Moseley, G. L. (2014). Exploring the roles of body ownership, vision and virtual reality on heat pain threshold. European Journal of Pain, 18(7), 900-901. doi: 10.1002/j.1532-2149.2014.483.x 
HealthMeasures. (2018). HealthMeasures scoring service powered by assessment center ${ }^{\mathrm{SM}}$. Retrieved from https://www.assessmentcenter.net/ac_scoringservice

Kim, A., Darakjian, N., \& Finley, J. M. (2017). Walking in fully immersive virtual environments: an evaluation of potential adverse effects in older adults and individuals with Parkinson's disease. Journal of NeuroEngineering and Rehabilitation, 14(1), 16. doi: 10.1186/s12984-017-0225-2

Law, M., Baptiste, S., Carswell, A., McColl, M. A., Polatajko, H., \& Pollock, N. (2014). Canadian Occupational Performance Measure (5th ed.). Ottawa: CAOT Publications.

Li, A., Montaño, Z., Chen, V. J., \& Gold, J. I. (2011). Virtual reality and pain management: current trends and future directions. Pain Management, 1(2), 147-157. doi: $10.2217 /$ pmt.10.15

Malloy, K. M., \& Milling, L. S. (2010). The effectiveness of virtual reality distraction for pain reduction: a systematic review. Clinical Psychology Review, 30(8), 1011-1018. doi: 10.1016/j.cpr.2010.07.001

Miller, K. J., Adair, B. S., Pearce, A. J., Said, C. M., Ozanne, E., \& Morris, M. M. (2013). Effectiveness and feasibility of virtual reality and gaming system use at home by older adults for enabling physical activity to improve health-related domains: a systematic review. Age and Ageing, 43(2), 188-195. doi: 10.1093/ageing/aft194

Parmelee, P. A., Katz, I. R., \& Lawton, M. P. (1991). The relation of pain to depression among institutionalized aged. Journal of Gerontology, 46(1), P15-P21. doi: 10.1093/geronj/46.1.P15

Pot-Kolder, R., Veling, W., Counotte, J., \& Van Der Gaag, M. (2018). Anxiety partially mediates cybersickness symptoms in immersive virtual reality environments. 
Cyberpsychology, Behavior, and Social Networking, 21(3), 187-193. doi:

10.1089/cyber.2017.0082

Pozeg, P., Palluel, E., Ronchi, R., Solcà, M., Al-Khodairy, A. W., Jordan, X., Kassouha, A. \& Blanke, O. (2017). Virtual reality improves embodiment and neuropathic pain caused by spinal cord injury. Neurology, 89, 1-10. doi: 10.1212/WNL.0000000000004585

PROMIS Health Organization and PROMIS Cooperative Group. (2016). PROMIS depression scoring manual. https://www.assessmentcenter.net/documents/PROMIS\%20Depression\%20Scoring\%20 Manual.pdf

Rossi, G. B., Serralvo, F. A., Joao, B. N., (2014). Content analysis. Brazilian Journal of Marketing, 13(39-48). doi: 10.5585/remark.v13i4.2701

Rustøen, T., Wahl, A. K., Hanestad, B. R., Lerdal, A., Paul, S., \& Miaskowski, C. (2005). Age and the experience of chronic pain: differences in health and quality of life among younger, middle-aged, and older adults. The Clinical Journal of Pain, 21(6), 513-523. doi: 10.1016/j.ejpain.2005.06.009

Schofield, P. (2007). Pain in Older Adults: Epidemiology, Impact and Barriers to Management. Reviews in Pain, 1(1), 12-14. doi:10.1177/204946370700100104

Schreier, M. (2012). Qualitative content analysis in practice. Thousand Oaks, CA: Sage

Shin, J.H., Kim, M., Lee, J., Jeon, Y., Kim, S., Lee, S., Seo, B., \& Choi, Y. (2016). Effects of virtual reality-based rehabilitation on distal upper extremity function and health-related quality of life: A single- blinded, randomized controlled trial. Journal of NeuroEngineering and Rehabilitation, 13. doi: 10.1186/s12984-016-0125-x 
Skevington, S., Lotfy, M., \& O'Connell, K. (2004). The World Health Organization's WHOQOL-BREF quality of life assessment: Psychometric properties and results of the international field trial. A Report from the WHOQOL Group. Quality of Life Research, 13(2), 299-310. doi: 10.1023/B:QURE.0000018486.91360.00

Tashjian, V. C., Mosadeghi, S., Howard, A. R., Lopez, M., Dupuy, T., Reid, M., Martinez, B., Ahmed, S., Dailey, F., Robbins, K, \& Rosen, B. (2017). Virtual reality for management of pain in hospitalized patients: Results of a controlled trial. JMIR Mental Health, 4(1). doi: $10.2196 /$ mental.7387

Tsang, A., Von Korff, M., Lee, S., Alonso, J., Karam, E., Angermeyer, M. C., ... \& Gureje, O. (2008). Common chronic pain conditions in developed and developing countries: Gender and age differences and comorbidity with depression-anxiety disorders. The Journal of Pain, 9(10), 883-891. doi: 10.1016/j.jpain.2008.05.005

Tsoi, K. K., Chan, J. Y., Hirai, H. W., Wong, S. Y., \& Kwok, T. C. (2015). Cognitive tests to detect dementia: a systematic review and meta-analysis. JAMA Internal Medicine, 175(9), 1450-1458. doi:10.1001/jamainternmed.2015.2152

WHOQOL Group. (1998). Development of the World Health Organization WHOQOL-BREF quality of life assessment. Psychological Medicine, 28(3), 551-558.

Wiederhold, B., Gao, K., Sulea, C., \& Wiederhold, M. (2014). Virtual reality as a distraction technique in chronic pain patients. Cyberpsychology, Behavior, and Social Networking, 17(6). doi: 10.1089/cyber.2014.0207

Williamson, A., \& Boggart, B. (2005). Pain: A review of three commonly used pain rating scales. Journal of Clinical Nursing, 14(7), 798-804. doi: 10.1111/j.13652702.2005.01121.x 
Figure 1. Virtual reality (VR) with head-mounted display and controllers. Monitor set up is available for supervisor to verbally guide subject throughout VR activities.

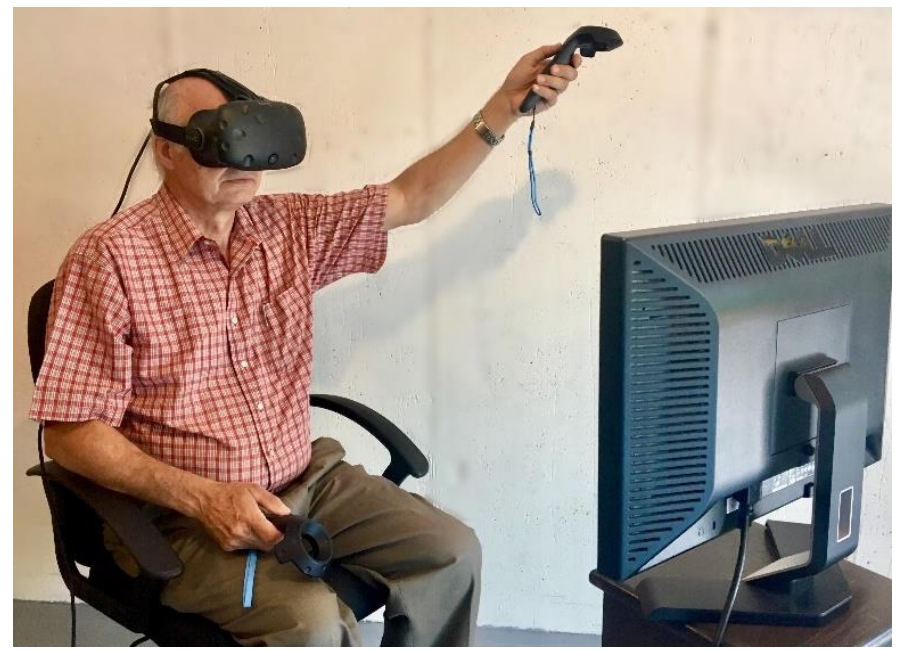


Table 1. Demographic distributions

\begin{tabular}{|l|c|}
\hline \multicolumn{2}{|c|}{ Baseline Characteristics (n=12) } \\
\hline \multicolumn{2}{|c|}{$\mathrm{n}(\%)$ or $\bar{x}(\mathrm{SD})$} \\
\hline Age & $70.2(3.6)$ \\
\hline (Female) & $8(66.7 \%)$ \\
\hline Race (Caucasian) & $4(33.3 \%)$ \\
\hline $\begin{array}{c}\text { (Decline to Answer) } \\
\text { Mini Cog score (x/5) }\end{array}$ & $11(91.7 \%)$ \\
\hline $\begin{array}{c}\text { At least weekly tech use } \\
\text { (Yes) }\end{array}$ & $1(8.3 \%)$ \\
\hline $\begin{array}{c}\text { (No) } \\
\text { Pain-related diagnosis } \\
\text { (Musculoskeletal) }\end{array}$ & $11(91.7 \%)$ \\
\hline (Neurological) & $1(8.3 \%)$ \\
\hline
\end{tabular}


Table 2. Post intervention (six week period) survey questionnaire content analysis results

\begin{tabular}{|c|c|c|}
\hline Questions & Positive Responses, n (\%) & Negative Responses, n (\%) \\
\hline $\begin{array}{l}\text { 1. Overall experience: } \\
\text { What was your experience with } \\
\text { learning the virtual reality (VR) } \\
\text { system? }\end{array}$ & $\begin{array}{l}12(100 \%) \\
\text { e.g. "Controls were easy - } \\
\text { instructions were easy to } \\
\text { follow" } \\
\text { "Pain lessened a lot! Got } \\
\text { my own VR system } \\
\text { because of this!" }\end{array}$ & $0(0 \%)$ \\
\hline $\begin{array}{l}\text { 2. Pain: } \\
\text { a. Do you think that VR } \\
\text { affected your pain level in } \\
\text { any way? If yes/no, please } \\
\text { explain how. }\end{array}$ & $\begin{array}{l}12(100 \%) \\
\text { e.g. "Yes, I did not feel } \\
\text { pain because I was so } \\
\text { engrossed in the VR } \\
\text { experience." }\end{array}$ & $0 \quad(0 \%)$ \\
\hline $\begin{array}{l}\text { b. Do you have any other } \\
\text { experiences with the VR } \\
\text { that you would like to } \\
\text { share? }\end{array}$ & $\begin{array}{l}6(87.3 \%) \\
\text { e.g. "Traveling the globe } \\
\text { was awesome." }\end{array}$ & $\begin{array}{l}1 \quad(14.3 \%) \\
\text { e.g. "Once when I was on a } \\
\text { motor cycle track I got } \\
\text { really quessy [sic]" }\end{array}$ \\
\hline $\begin{array}{l}\text { 3. Symptoms: } \\
\text { Did you experience any } \\
\text { symptoms such as headache, } \\
\text { eyestrain, or nausea after using } \\
\text { the VR system? }\end{array}$ & $\begin{array}{l}7(58.3 \%) \\
\text { e.g. "No negative } \\
\text { symptoms" }\end{array}$ & $\begin{array}{l}5 \quad(41.7 \%) \\
\text { e.g. "No, except being shot } \\
\text { into the sky on a gummy } \\
\text { bear rocket made me a } \\
\text { little dizzy" "Slight fear of } \\
\text { great heights" }\end{array}$ \\
\hline $\begin{array}{l}\text { 4. Usage: } \\
\text { a. Would you continue to use } \\
\text { VR in your leisure time? } \\
\text { b. What type of supports (i.e. } \\
\text { staff, volunteers, peers, } \\
\text { different VR system/ } \\
\text { equipment) would } \\
\text { you suggest to continue to use } \\
\text { VR? }\end{array}$ & $\begin{array}{l}11(91.7 \%) \\
\text { e.g. "Most certainly" } \\
\text { "Hopefully!" } \\
\text { e.g. N/A, responses were } \\
\text { neither positive nor } \\
\text { negative }\end{array}$ & $\begin{array}{l}1(8.3 \%) \\
\text { e.g. "Maybe" }\end{array}$ \\
\hline $\begin{array}{l}\text { 5. Recommendation: } \\
\text { Would you recommend another } \\
\text { member to try the VR system? }\end{array}$ & $\begin{array}{l}12(100 \%) \\
\text { e.g. "Would definitely } \\
\text { recommend } \\
\text { wholeheartedly" }\end{array}$ & $\begin{array}{l}0(0 \%) \\
1\end{array}$ \\
\hline
\end{tabular}


Table 3. Comparison of outcomes before and after virtual reality intervention, over six weeks

\begin{tabular}{|l|c|c|c|c|c|}
\hline $\begin{array}{l}\text { Outcome } \\
\text { Assessments }\end{array}$ & Pre $\bar{x}(\mathrm{SD})$ & Pre Median (IQR) & Post $\overline{\mathrm{x}}(\mathrm{SD})$ & $\begin{array}{c}\text { Post Median } \\
(\mathrm{IQR})\end{array}$ & $p$ \\
\hline $\begin{array}{l}\text { NPRS (Pre } \\
\text { Session 1 and } \\
\text { Post Session 12) }\end{array}$ & $3.5(1.73)$ & $3(2,4.5)$ & $0.9(1.62)$ & $0(0,1.25)$ & $0.002^{*}$ \\
\hline PROMIS@ & $53.5(16.11)$ & $54.5(42,62.25)$ & $49.1(14.03)$ & $43.5(39.75,59.5)$ & 0.33 \\
\hline WHOQOL-BREF & & & & & \\
Overall Health & $8.42(1.24)$ & $9(8,9)$ & $8.33(1.37)$ & $8.5(8,9)$ & 0.66 \\
Physical & $14.42(4.25)$ & $15.5(11.75,16.25)$ & $16.08(3.90)$ & $15(13.75,19)$ & 0.08 \\
Psychological & $17.25(3.52)$ & $17.5(16,19)$ & $18.50(4.01)$ & $20(16.75,20.5)$ & 0.15 \\
Social & $11.17(1.80)$ & $11(11,12)$ & $11.33(2.31)$ & $11(10.5,12.5)$ & 0.87 \\
Environment & $32.92(6.01)$ & $34(31.25,37.25)$ & $33.58(4.42)$ & $33(31.5,36)$ & 0.92 \\
\multicolumn{1}{|l}{} & & & & \\
\hline
\end{tabular}

*Indicates statistical significance

Note: NPRS= Numerical Pain Rating Scale, PROMIS $®=$ Patient-Reported Outcomes

Measurement Information System - Emotional Distress - Depression, WHOQOL-BREF= World Health Organization Quality of Life Scale Brief Version 